\title{
Pre-Detection of Kitchen Fires due to Auto-Ignition of Cooking Oil and LPG Leakage in Indian Kitchens
}

\author{
AKSHAY JAIN ${ }^{1}$, PRATEEK NYATI ${ }^{1}$, NAKUL NUWAL ${ }^{1}$, ADNAN ANSARI $^{2 a}$, CHINMAY GHOROI $^{1}$, \\ PRAVINRAY D. GANDHI ${ }^{2 b}$ \\ ${ }^{1}$ Safety Center, Indian Institute of Technology Gandhinagar, Ahmedabad - 382424, India \\ ${ }^{2 a}$ Underwriters Laboratories (India), Bangalore - 560066, India \\ ${ }^{2 b}$ Underwriters Laboratories Inc., Northbrook, IL, 60062, USA
}

\begin{abstract}
Presence of cooking oils and Liquefied Petroleum Gas (LPG) make it an ideal combination for fire hazard in Indian kitchen. Approximately 16\% of domestic fire accidents in India originate from the kitchens. In the present work, a microcontroller based fire detection system is designed to collect data of the parameters (e.g., temperature, concentration of gases) around the Indian kitchen cooking appliances due to oil heating and alert the possible fire event. Experiments were conducted by heating cooking oils typically used in India such as sunflower, soybean, groundnut and mustard oil. The kitchen environment was instrumented to measure temperatures and carbon monoxide concentrations which were collected using a data acquisition system. Based on the observations and analysis of the experimental data, an algorithm was developed to predict potential occurrence of fire. The algorithm includes $\mathrm{CO}$ monitoring in the kitchen ventilation (exhaust). The algorithm is incorporated in a microcontroller based fire detection kit to provide a multilevel response to the fire threat. It can, for example, (i) alert the home occupant through an alarm; (ii) send Short Messages (SMS); and (iii) cut off the LPG (fuel) supply to cooktop. The system was also used to monitor LPG concentration (LPG Sensor) and unattended cooking (Presence or absence of human beings using PIR motion sensor) in the kitchen. The developed fire safety system is a modular and low cost kit which is intended to save loss of property and lives due to kitchen fires.
\end{abstract}

KEYWORDS: ignition, detection, kitchen fire, fire protection, oil heating, CO sensor, safety, LPG

\section{INTRODUCTION}

Kitchens are more than just a place for cooking food. They are food research laboratory where many experiments are done (although not all are documented!). However, this is exactly the same place which is the source of many domestic fire incidents. National Fire incident reporting system (NFIRS) data of US shows that kitchen fires and cooking related fire is the leading cause of the building fires which is steadily increasing $[1,2]$. In United States, National Fire Protection Association (NFPA) has reported that $85 \%$ of fire deaths and $82 \%$ of injuries occurred in the home structure fires which involved cooking equipment are due to Ranges [3]. NFPA's latest estimates of home cooking fires 2010 Fact Sheet [4] reported that cooking led to an estimated 1,56,400 home structure fires, 420 deaths, 5,310 injuries and about $\$ 993$ million loss in direct property damage. The report suggests that cooking caused almost $44 \%$ of reported residential fires, $16 \%$ home fire deaths, $40 \%$ home fire injuries and $15 \%$ of the direct property damage in 2010 . The problem is also severe in other countries, kitchen fires account for over 60 per cent of fires in people's homes in London. From 2005-10 there were over 17,500 kitchen fires in London, causing over 2600 injuries and 24 deaths [5]. The number of kitchen fires in India is also substantial among all fire cases registered by National Bureau of crime records [6]. The report from World Health Organization (WHO) [7] also shows that over 10,00,000 people are moderately or severely burnt (injured) every year in India due to cooking equipment.

In 2010 and 2011 total numbers of reported kitchen fire were 4912 and 4096 respectively and it is almost $16 \%$ of all types of fire cases registered in India. In 2011 alone (Fig. 1), the total number of fatalities due to kitchen fire is about 4005 which constitutes about 3126 females (78.05\%). Also, in the same year, 3250 cases of injuries of various types were reported due to fire [6]. 


\section{No. of Fatalities due to fire, 2011 (India)}

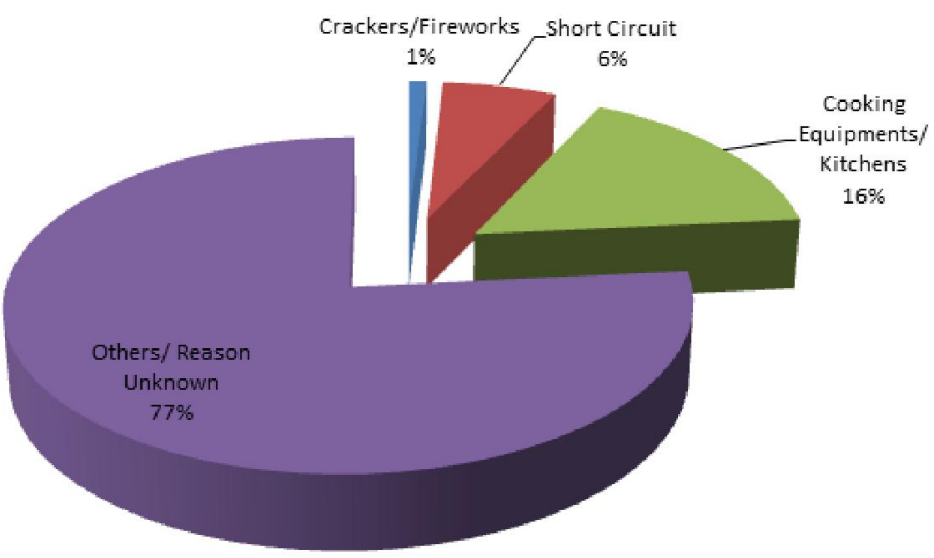

Fig. 1. Recorded fatalities due to fire in India, 2011, [6]

The above numbers are reported cases only. However, this number is much higher in reality as $77 \%$ of fatalities occurred due to unknown reasons and many day-to-day injuries are not reported until they are big enough to cause damage. This is mainly due to lack of proper fire incident reporting system in India. However, the high number of fire incident in kitchen inspires the present work on detection and suppression of fire event in Indian kitchens. It motivated Safety Center, IIT Gandhinagar and Underwriters Laboratories Chicago to collaborate and work towards kitchen fire safety.

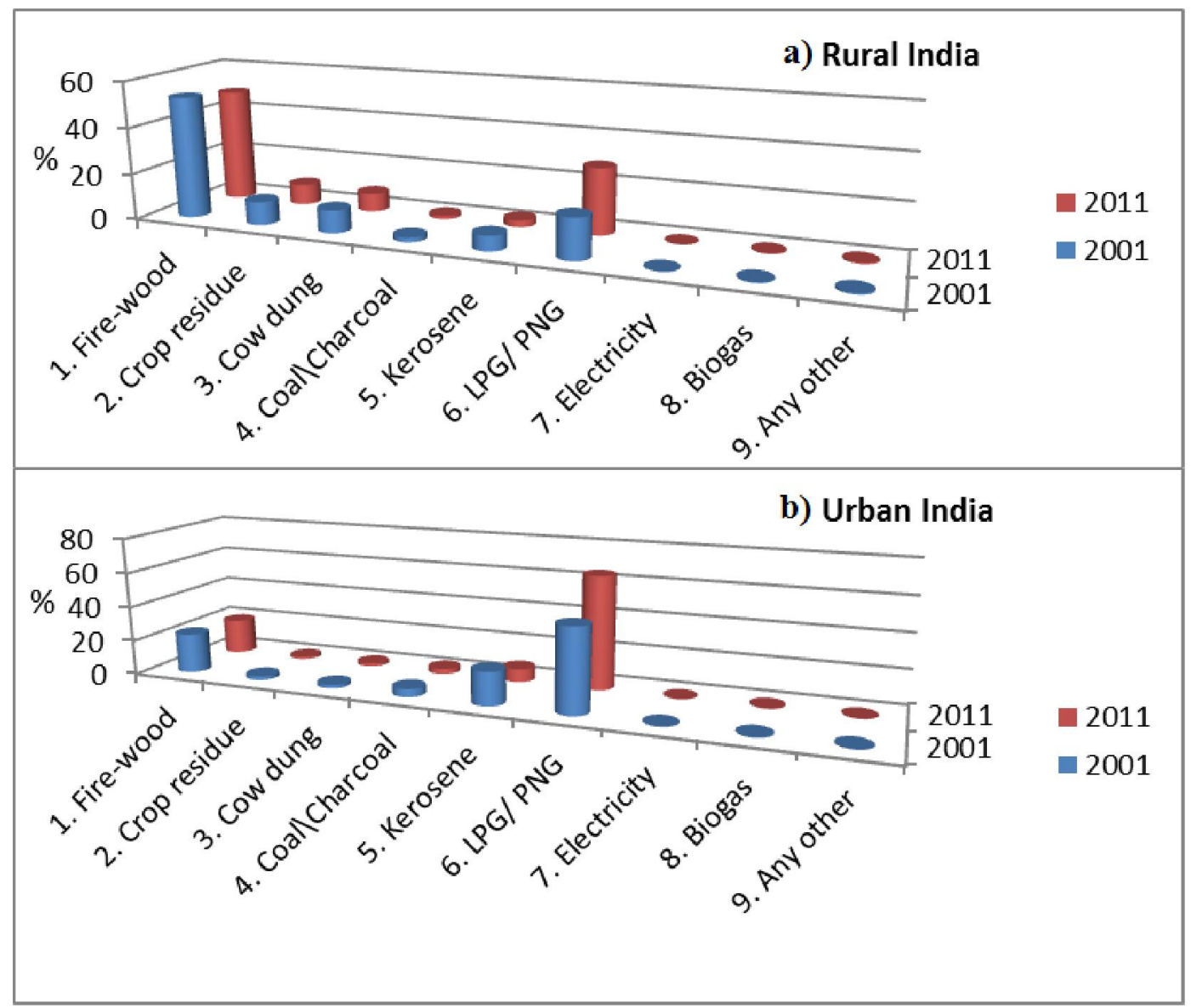


Cooking practices in India varies from rural to urban households. While the main fuel for urban household in India is gaseous fuel - LPG, the rural cooking system is mainly based on the solid fuel such as fire wood, cow dung etc. However, Census 2001-2011 [8] showed (Fig. 2) that there is a sharp increase in the use of LPG as a cooking fuel both in urban (48\% to $65 \%)$ and rural India (5.7\% to $11.4 \%)$. Generally, cooking pots, pans, containers, cutlery with a portable cook top is placed over the LPG stove which is directly connected to a LPG cylinder or a to a LPG gas pipe line. LPG is also used in other countries for cooking such as Hong Kong, Brazil, Indonesia etc. [9]. Indian kitchens get very hot and smoky during addition of spices in hot oil. In fact, it is the integral part of most of the Indian recipes. Use of fire wood or similar solid fuel in rural India is an additional source to produce more amount of smoke. Though most of the kitchens are equipped with a chimney or a simple exhaust fan, there exists observable amount of smoke in the kitchen. Similar to residential or domestic kitchen, the kitchen in hotels and restaurants also encounter more or less similar conditions in India. Many of these kitchens do not have proper safety system in place. In fact there are several cases of fire in kitchens in hotels and restaurants. Commercial and other cooking practices also resembles residential cooking in some aspects like Fuel - LPG, use of oil, methods of cooking, but scales are different. However, residential kitchen fires are much higher in number than commercial kitchen fires [1]. This particular study is focused more towards study of Indian cooking conditions and kitchen fire.

Most of the reported cases of the kitchen fire are due to fats, oils, and grease [4]. They are flammable at higher temperatures and easily spill during cooking. Also stove burst, leakage of LPG from cylinder (or gas connections) or the auto ignition of oil [6] are other reasons behind the accidents. A lot of times people leave cooking pans/ dishes unattended in ovens or cooktop resulting in big accidents. In this regard, use of alarm system is useful to alert people. There are few studies in the literature for fire detection and suppression of fire. Cestari et al. [10] studied advanced fire detection algorithms where they concluded that $\mathrm{CO}$ measurement in some cases provide a high degree of Nuisance immunity and also provides faster detection. Gottuk et al. (2002) [11] studied the feasibility of reducing false alarms and increasing the sensitivity using smoke and CO sensor together. They found that multi-sensor signal conditioning scheme using smoke and $\mathrm{CO}$ sensor improved the fire detection capabilities in number of flammable materials such as smoldering wood, flaming fabric and cooking fire. There are number of research for estimation and reduction of the fire detection time to design the required safety egress time (RSET) or determine the time to start the aerosol detector [12] including the video based detector fire detection system [13]. Thus, faster detection system provides more time to save lives. However, these detectors are designed to respond only after the fire event. Once fire catches, it is difficult to control fire even after the early detection and more so when the fuel is oil and LPG. Indian kitchens are quite different from other kitchens all over the world and there have been no studies related to detection of kitchen fire concerning Indian kitchens.

The objective of the present study to is to develop a safety system which will extract real time information during cooking and alert any anticipated fire event including an automatic fuel cut mechanism which stops the fuel (LPG) supply to avoid any fire event. A typical Indian kitchen was set up in Fire Engineering lab. Four different vegetable oils were heated in a saucepan on the single burner LPG stove which was connected to a LPG cylinder. Oil temperatures and concentration of carbon monoxide were measured using appropriate sensors. The generated data was collected using a data acquisition system and stored in a PC connected to the system. Based on the observations and systematic analysis of the experimental data, a fire safety system was designed and prototyped. The kit was also integrated with safety alarm for any LPG leakage and unattended cooking. The designed safety system is a modular and low cost kit which is intended to save loss of lives and property due to kitchen fire.

\section{EXPERIMENTS}

As sunflower, soybean, mustard and groundnut oil consumption in Indian food is about $40 \%$, these oils were used for the experiment [14]. Table 1 shows the different physical properties of all the oils used in the experiment. The metric label Saturation (\%) refers to percentage of saturated triglycerides present. Smoke Point $\left({ }^{0} \mathrm{C}\right)$ refers to the point at which observable change in the smoke was observed initially. The density of all the types of oil was measured by measuring mass for a fixed volume of $100 \mathrm{ml}$. 
Table 1. Properties of four different oils

\begin{tabular}{cccccc}
\hline $\begin{array}{c}\text { Sr. } \\
\text { No. }\end{array}$ & $\begin{array}{c}\text { Type of } \\
\text { Oils }\end{array}$ & $\begin{array}{c}\text { Saturation } \\
\mathbf{( \% )}\end{array}$ & $\begin{array}{c}\text { Smoke point } \\
\mathbf{( \mathbf { 0 }}^{\mathbf{0}} \mathbf{)}\end{array}$ & $\begin{array}{c}\text { Density } \\
\mathbf{( k g / \mathbf { m } ^ { 3 } )}\end{array}$ & Supplier \\
\hline 1 & Groundnut & 11 & 246 & 958.1 & Adani Wilmar \\
2 & Sunflower & 13 & 254 & 966.2 & Ltd. - Fortune, \\
3 & Mustard & 15 & 241 & 970.1 & India \\
4 & Soybean & 18 & 231 & 958.1 & \\
\hline
\end{tabular}

Experiments were conducted with $100 \mathrm{ml}$ of each type of oil in a stainless steel pan (Fig. 4). Pan along with the oil was heated at full throttle (1.5-2 LPM) on a LPG gas stove and was allowed to be overheated to reach the auto ignition point and eventually catch fire. Each of the oil was allowed to heat till it auto ignites and corresponding temperature, time and $\mathrm{CO}$ concentration was noted. All the experiments were started from room temperature. After the oil caches fire, gas connection was disconnected. A schematic diagram of experimental setup is shown in Fig. 3. The data generated during experiments were collected using a data acquisition system (which uses Arduino Micro controller and other accessories mentioned in table 2 and 3 ) which collected the oil temperatures, carbon monoxide (CO) concentration, LPG Concentration as well as presence of cook. Analysis of collected data for four different oils is discussed in the next section.

As mentioned, the system is based on multi sensor approach which is instrumented to measure Carbon mono-oxide concentration, LPG concentration, Values from PIR sensor and Temperature (not a part of the final system). $\mathrm{CO}$ concentration was measured using a CO sensor (HUWAI, MQ7) which was installed inside the duct of the chimney with an extraction rate of $700 \mathrm{~m}^{3} / \mathrm{hr}$. To measure the oil temperature a thermocouple was dipped inside the oil at the center of the pan which was about 2-5 $\mathrm{mm}$ above the base. To measure the presence of motion and LPG gas leak, a PIR motion sensor and a LPG sensor (HUWAI, MQ6) were attached in front of the platform. Table 2 describes the properties and other details of the sensors used in the following system. Though, thermocouple was used for measurement of temperature, it will not be a part of the final system. The measurement of temperature was used to study the proximity of Auto ignition temperature of different oils with the temperatures involved in normal cooking practices in Indian kitchens. Apart from sensors, the stove was connected to a LPG gas cylinder through a control valve which was connected to the Microcontroller. The control valve was used to cut the LPG supply to the stove. Details of the experimental set up along with the sensor position are shown in Fig. 3. Table 3 shows the cost of other components used in the system.

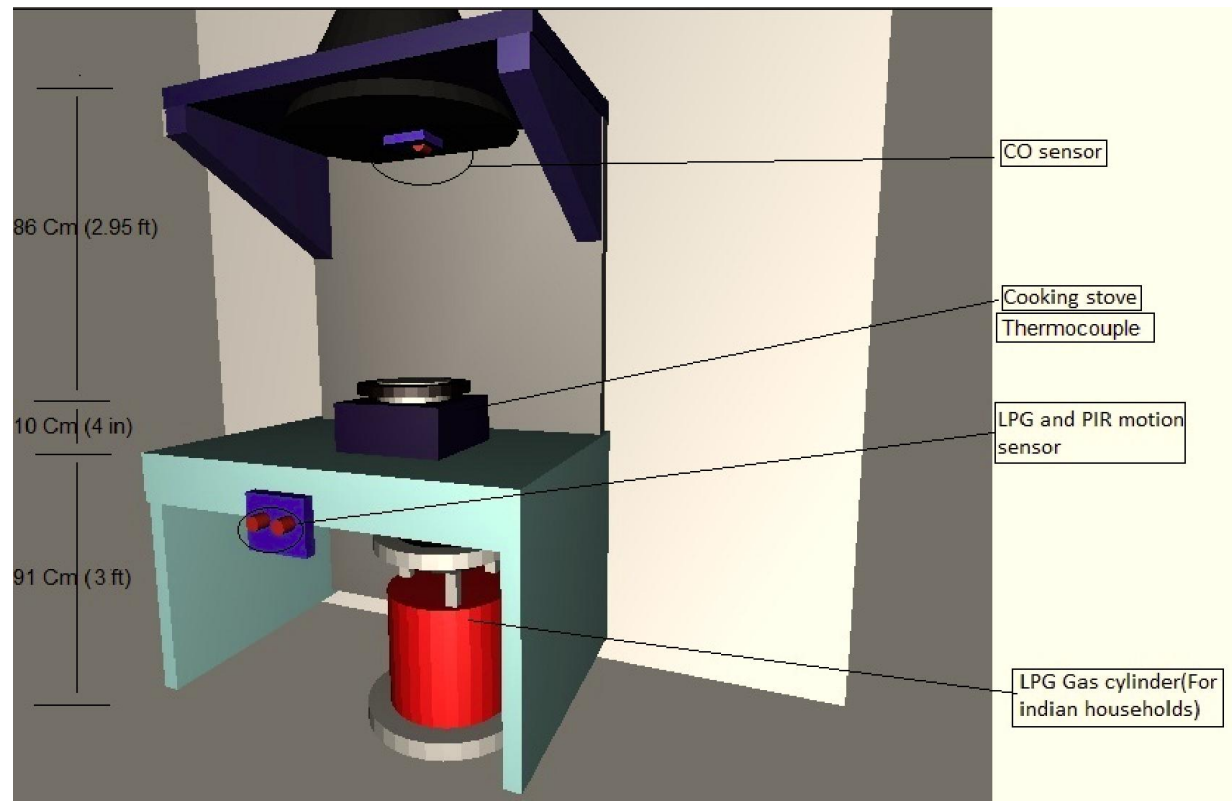

Fig. 3. Experimental Setup 


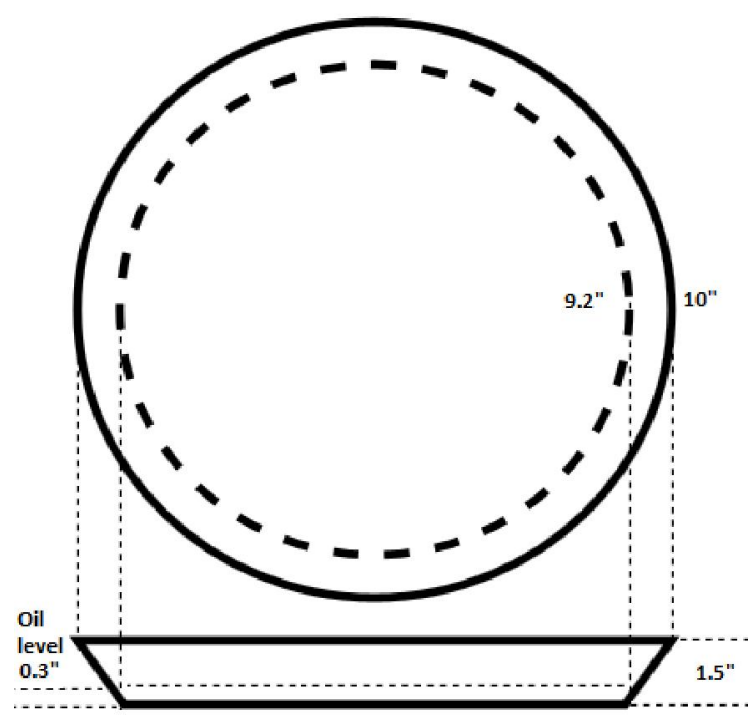

Fig. 4. Dimension of stainless steel cooking pan

Table 2. Different sensors and their details

\begin{tabular}{|c|c|c|c|c|}
\hline Sensor Properties & $\begin{array}{c}\text { K Type } \\
\text { Thermocouple }\end{array}$ & MQ 7 CO sensor & MQ 6 LPG sensor & $\begin{array}{l}\text { PIR Motion } \\
\text { Sensor }\end{array}$ \\
\hline \multirow{3}{*}{$\begin{array}{l}\text { Calibration } \\
\text { Approximate cost } \\
\text { in Indian Markets }\end{array}$} & Oil Temperature & $\begin{array}{c}\text { Carbon Monoxide } \\
\text { Concentration } \\
\text { (PPM) }\end{array}$ & $\begin{array}{l}\text { Liquefied Petroleum } \\
\text { Gas Concentration } \\
\text { (PPM) }\end{array}$ & $\begin{array}{c}\text { Motion } \\
\text { (Presence of } \\
\text { Human Beings) }\end{array}$ \\
\hline & Not Required & $\begin{array}{c}\text { Calibrated at } 100 \\
\text { PPM CO }\end{array}$ & $\begin{array}{c}\text { Calibrated at Pure } \\
\text { LPG } \\
\end{array}$ & NA \\
\hline & Rs. $150(3 \$)$ & Rs. $100(2 \$)$ & Rs. $100(2 \$)$ & Rs. $100(2 \$)$ \\
\hline \multirow{4}{*}{$\begin{array}{c}\text { Data Acquisition } \\
\text { Time Period } \\
\text { Units of } \\
\text { Measurement } \\
\text { Conversion }\end{array}$} & Manual & $\begin{array}{l}\text { Using Arduino } \\
\text { Microcontroller }\end{array}$ & $\begin{array}{l}\text { Using Arduino } \\
\text { Microcontroller }\end{array}$ & $\begin{array}{l}\text { Using Arduino } \\
\text { Microcontroller }\end{array}$ \\
\hline & Every 10 Seconds & Every Second & Every Second & Every Second \\
\hline & ${ }^{\circ} \mathrm{C}$ & Analog (Volts) & Analog (Volts) & $1 / 0$ \\
\hline & NA & PPM & PPM & NA \\
\hline
\end{tabular}

Table 3. Cost of other components of the system

\begin{tabular}{cccc}
\hline S. No. & Other Components & Cost & Remarks \\
\hline 1 & Arduino Microcontroller & Rs. $300 /-(5 \$)$ & $\begin{array}{c}\text { Other cheaper controller could be taken } \\
\text { into consideration }\end{array}$ \\
2 & $\begin{array}{c}\text { Pneumatic valve } \\
\text { (for gas shut off) }\end{array}$ & Rs. $500 /-(10 \$)$ & $\begin{array}{c}\text { Other alternative/ cheaper option could } \\
\text { be considered }\end{array}$ \\
\hline
\end{tabular}

\section{RESULTS AND DISCUSSIONS}

Fig. 5-8 shows the oil temperature and $\mathrm{CO}$ concentration vs. time for all four oils. From the plots it was found that oil temperature increases with time as expected. After it reached a certain temperature, there was a small peak in the temperature curve i.e. the temperature at which the oil produce sufficient vapor to catch fire automatically without any ignition source. This is known as auto ignition temperature (AIT). The fire determination was based on visual observation throughout the study. After the fire was extinguished, the oil temperature decreased slowly as the heating source (LPG supply) was closed. The observation was similar for all the oils. The maximum temperature at which oils are ignited found to fall within the range of $325-$ $350{ }^{\circ} \mathrm{C}$ (Fig. 9). Though there may be some variation of the auto ignition temperature depending upon the FIRE SAFETY SCIENCE-PROCEEDINGS OF THE ELEVENTH INTERNATIONAL SYMPOSIUM pp. 1285-1297 
oil properties and tests conditions, the temperature range for AIT gives a fair idea about the range of temperature where possible fire event occurs for these cooking oils. Another observation was that with increasing the temperature, amount of smoke on top of the oil pan increased (Fig. 10). This is mainly due to incomplete combustion and increase in the vaporization rate of oil.

The concentration of $\mathrm{CO}$ is also shown in the same plot (Fig. 5-8). It was observed that with increase in temperature, amount of $\mathrm{CO}$ increased due to incomplete combustion. This was also found in terms of observable change in smoke density. Figure 5-8 shows that the increase of CO continued till the ignition point where it shows maximum CO concentration (Fig. 11 shows the separate plot of CO for each oil). After the auto ignition, the amount of concentration of $\mathrm{CO}$ decreases steadily as the temperature reduced. Table 4 shows the auto ignition temperature, time to catch fire the oil (after starting the experiment) and maximum $\mathrm{CO}$ concentration at the auto ignition temperature.

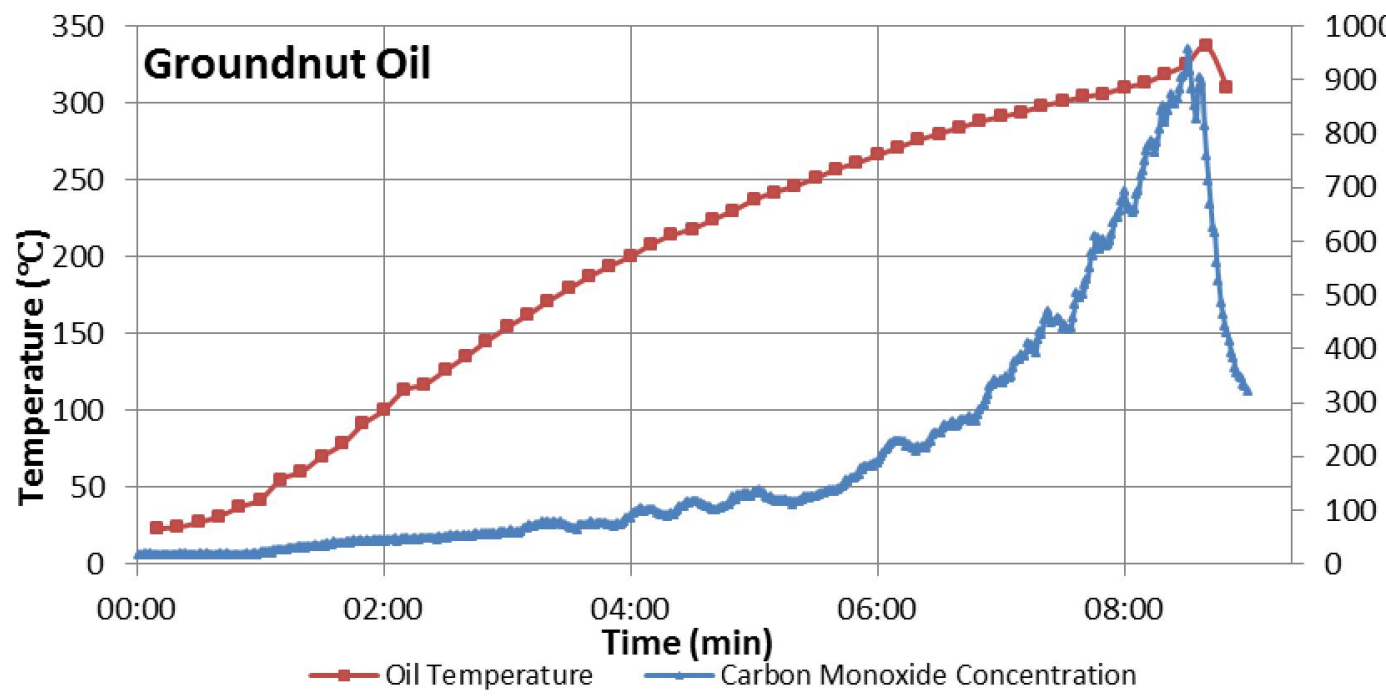

Fig. 5. Oil temperature and CO concentration (in exhaust gases) for Groundnut oil

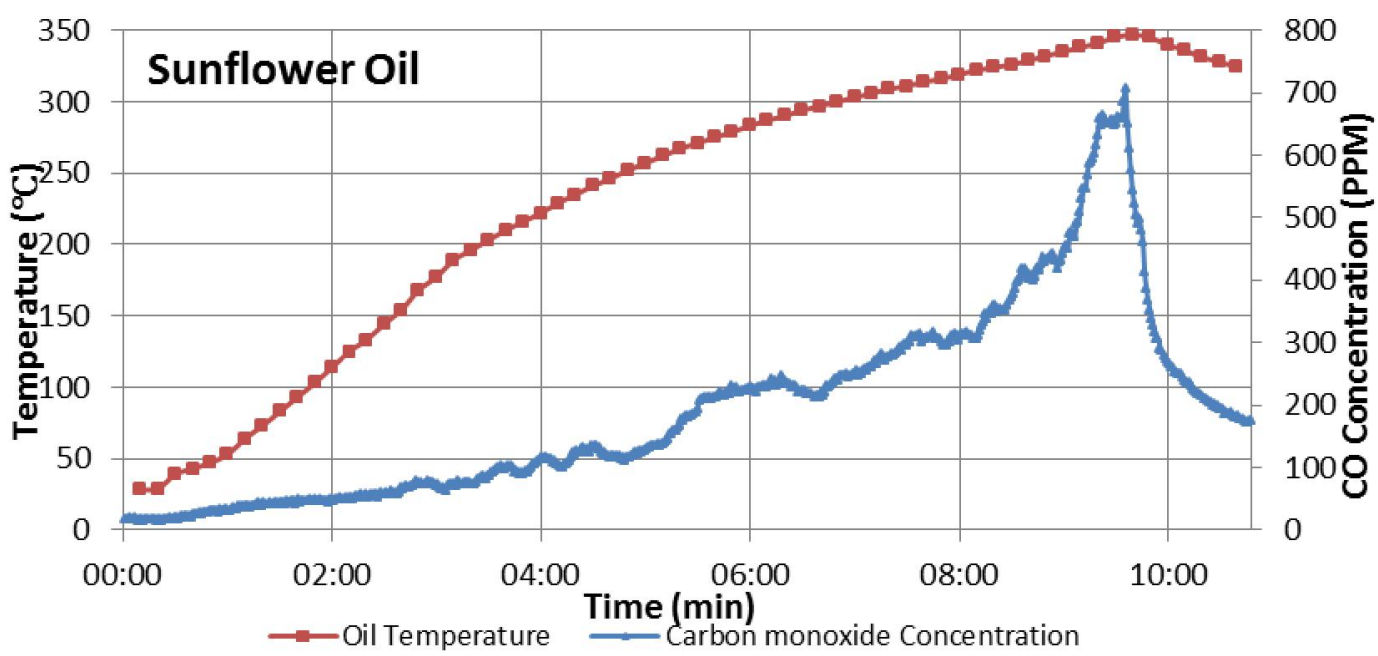

Fig. 6. Oil temperature and $\mathrm{CO}$ concentration (in exhaust gases) for the sunflower oil 


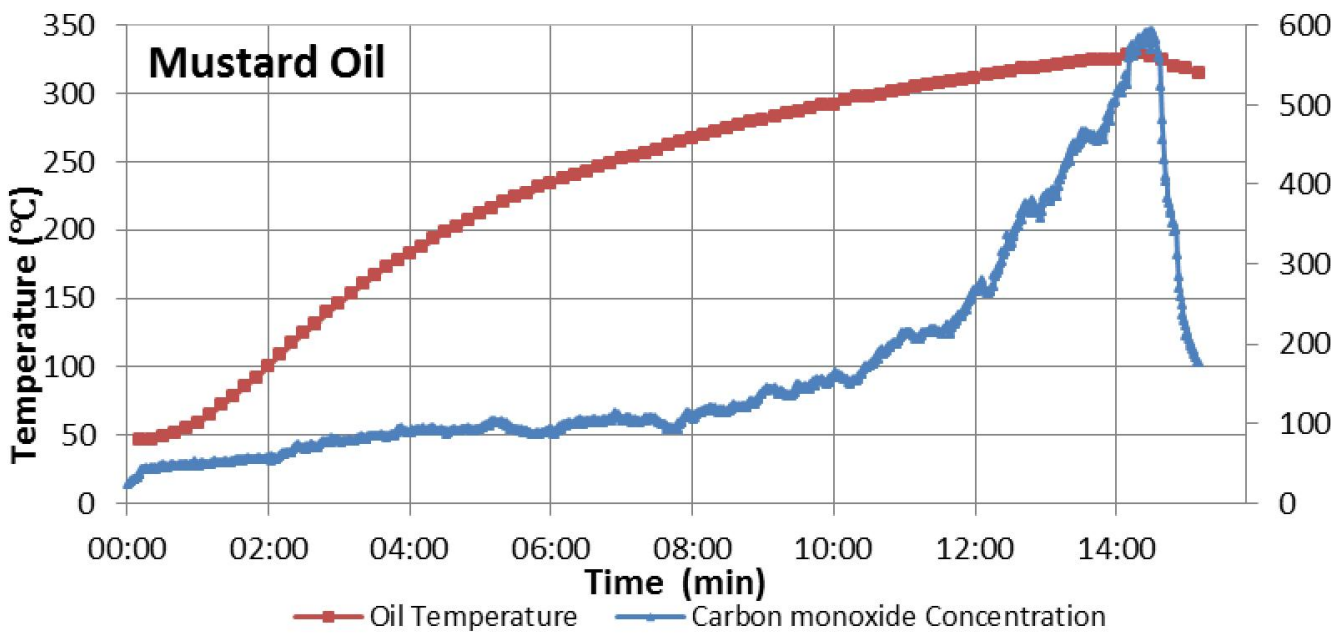

600

500

Fig. 7. Oil temperature and $\mathrm{CO}$ concentration (in exhaust gases) for mustard oil

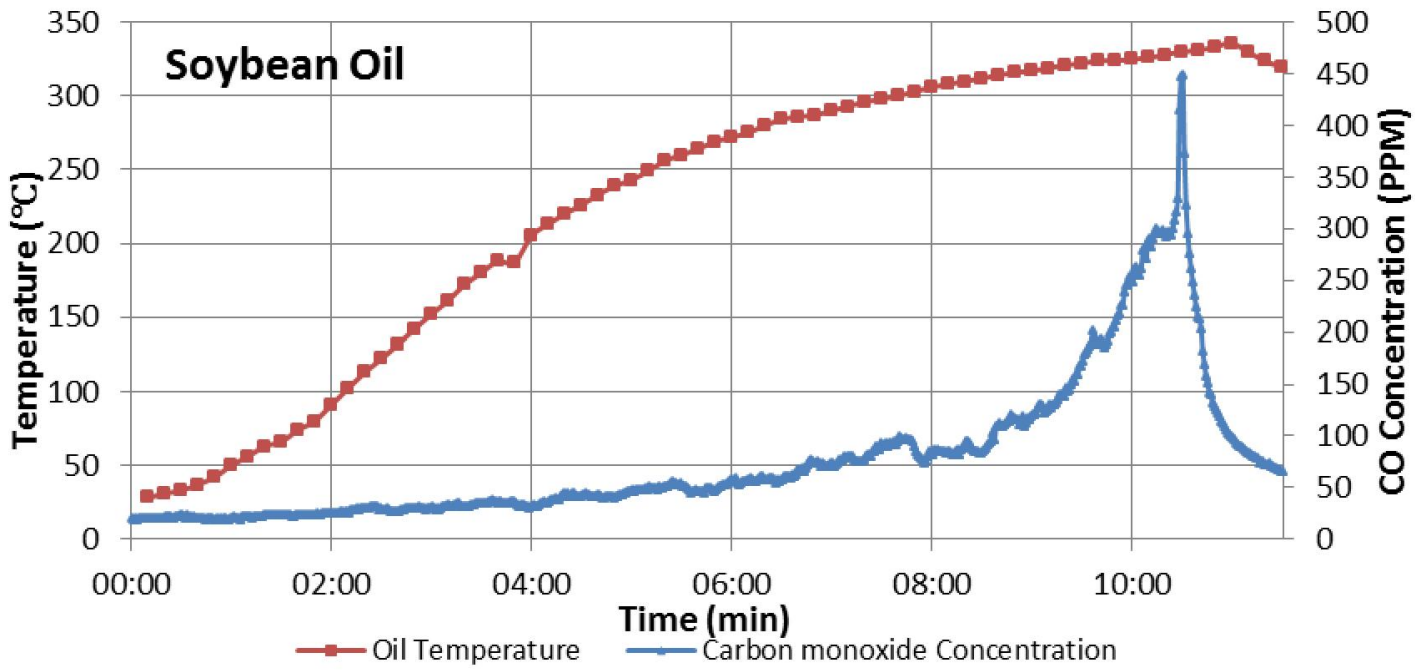

Fig. 8. Oil temperature and $\mathrm{CO}$ concentration (in exhaust gases) for soybean oil

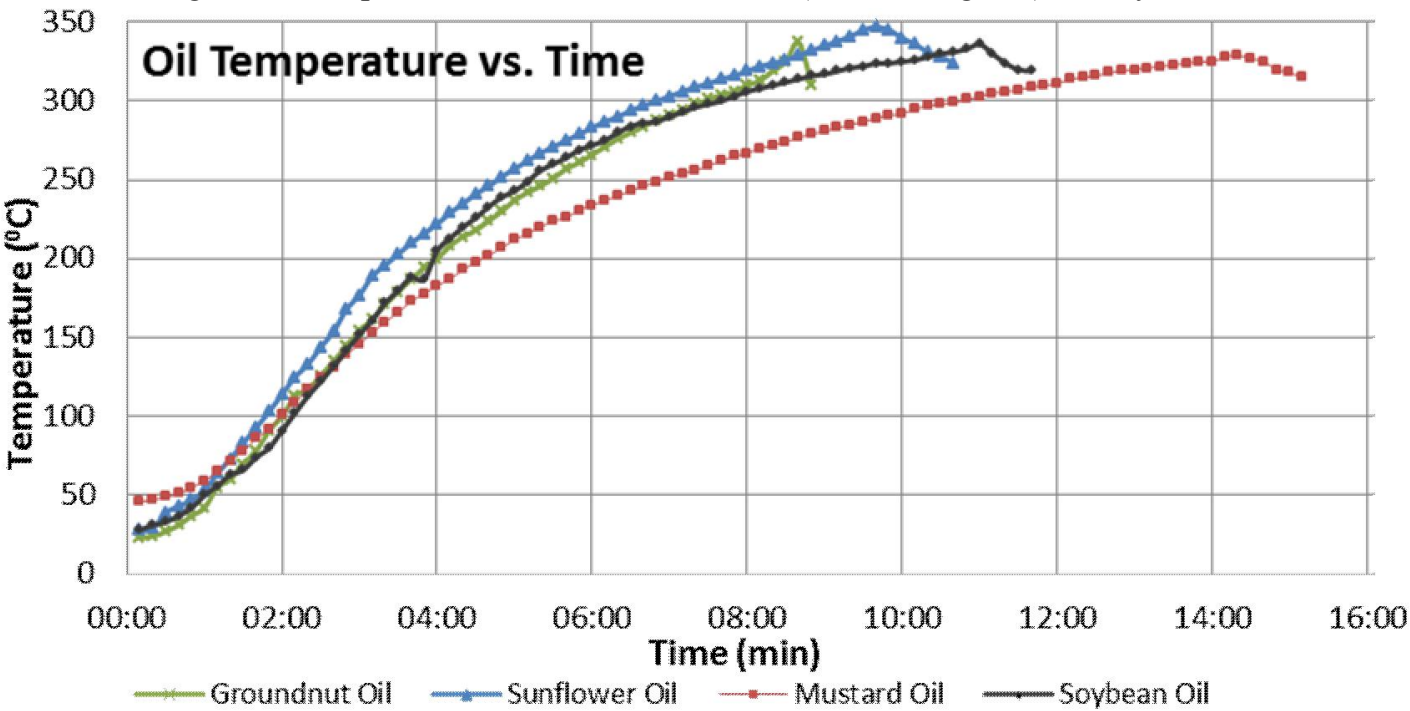

Fig. 9. Oil temperature vs. time for different oils 


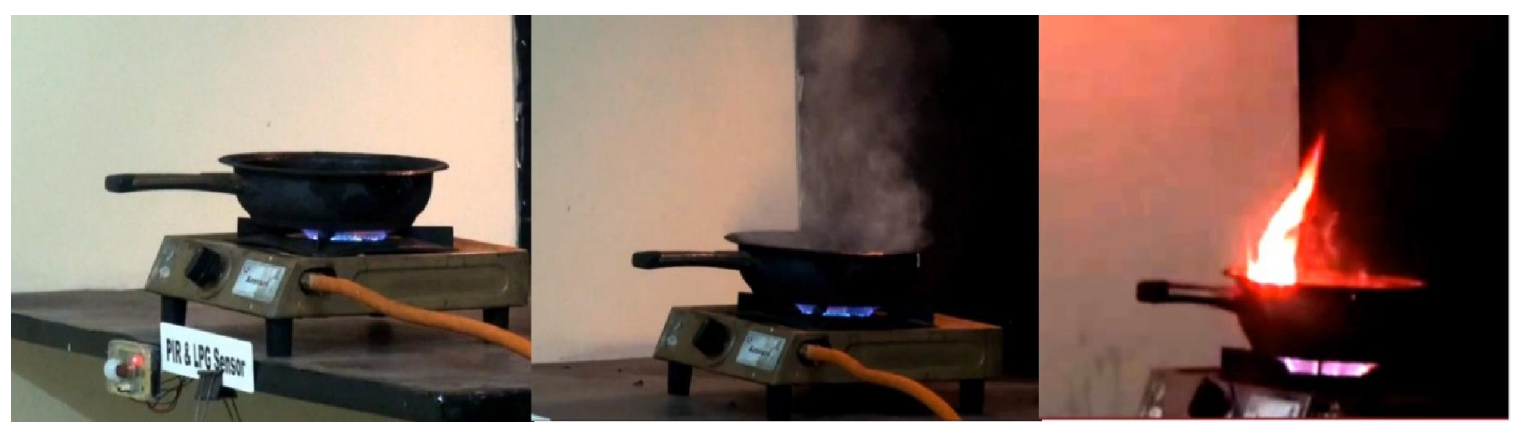

Fig. 10. Images of oil heating system at different time(s)

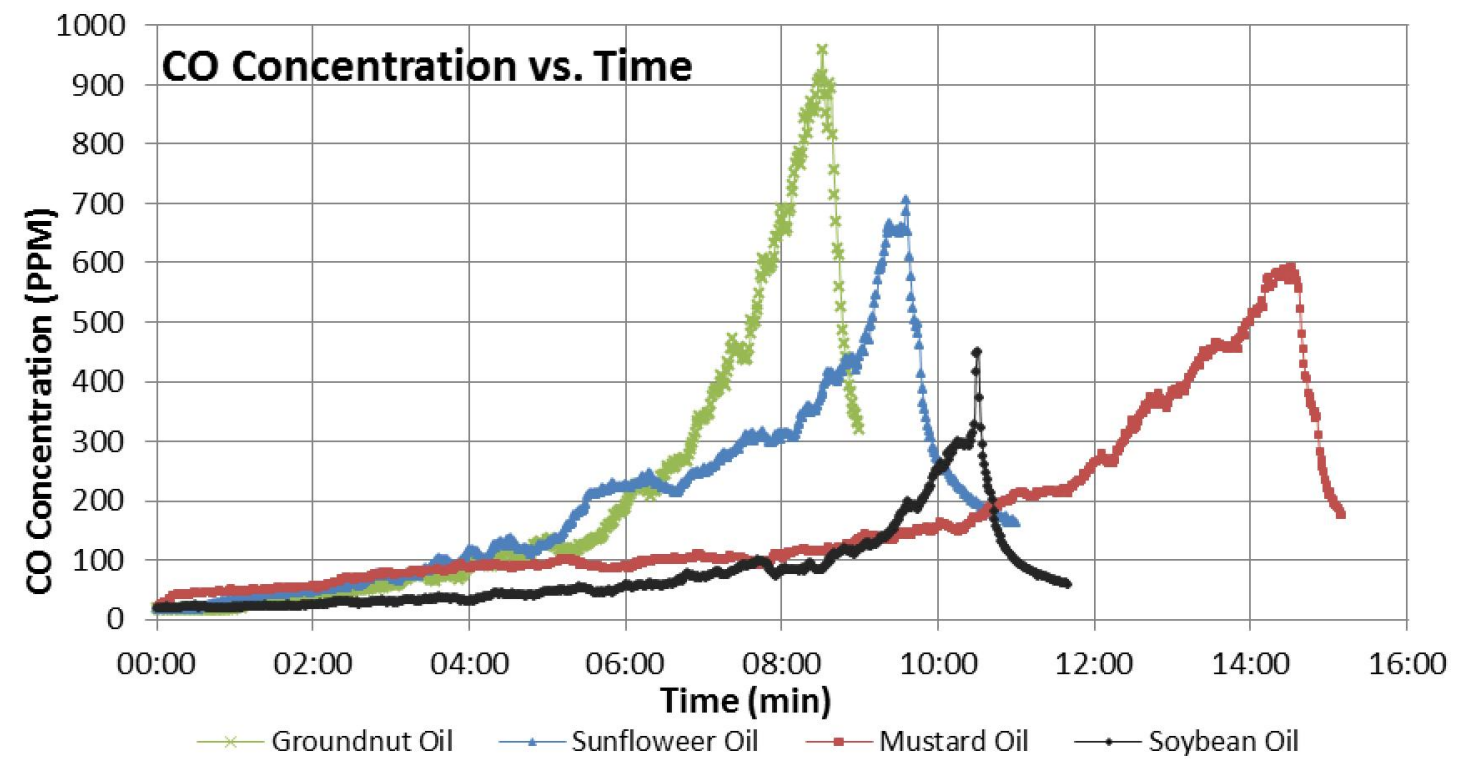

Fig. 11. CO concentration vs. Time for different oils

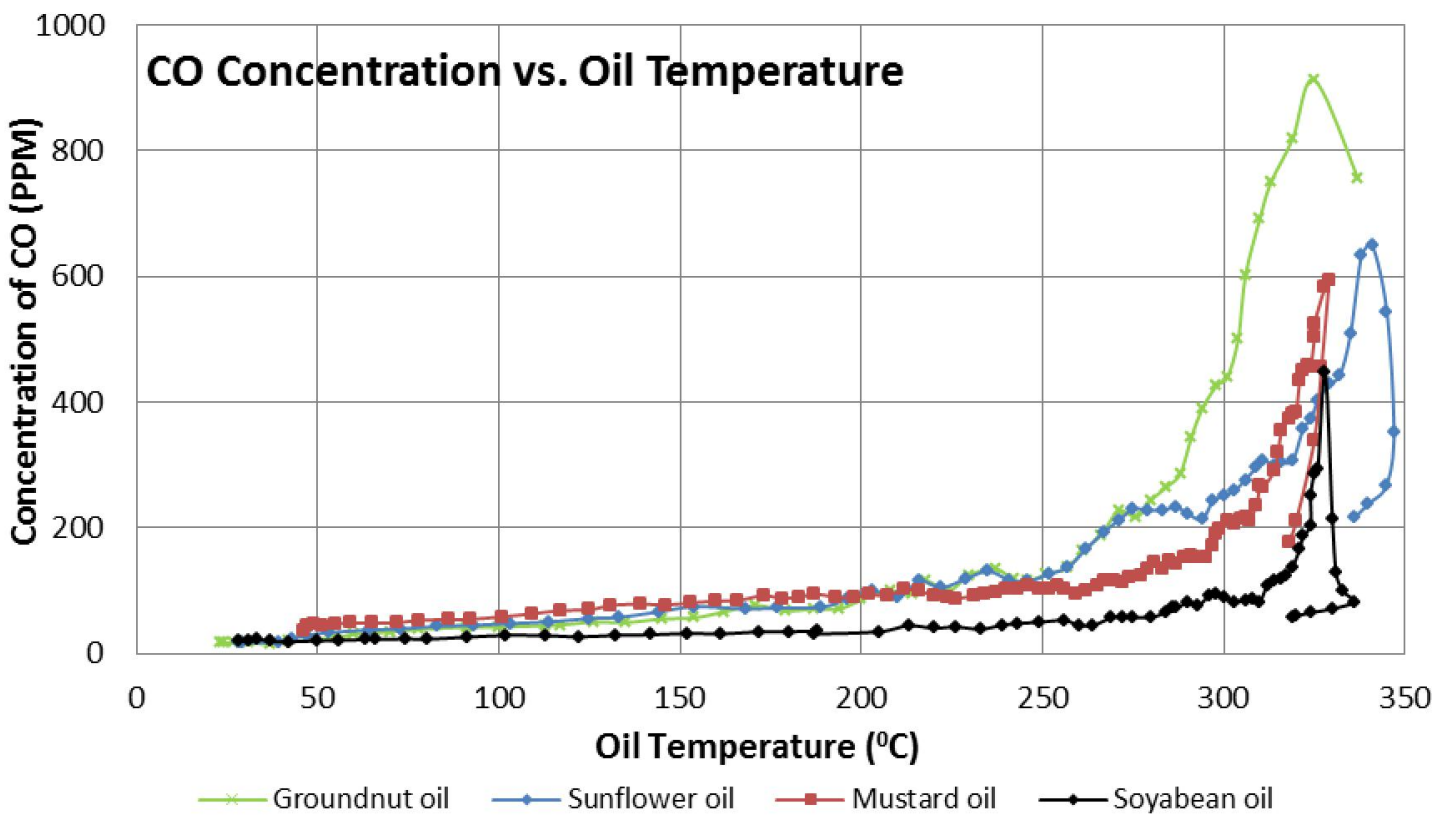

Fig. 12. Effect of oil temperature on $\mathrm{CO}$ concentration which was measured at chimney FIRE SAFETY SCIENCE-PROCEEDINGS OF THE ELEVENTH INTERNATIONAL SYMPOSIUM pp. $1285-1297$ 
Table 4. Auto ignition temperature, time of ignition and concentration of $\mathrm{CO}$ when oil catches fire

\begin{tabular}{ccccc}
\hline Sr. No. & Oil Types & $\begin{array}{c}\text { Auto Ignition } \\
\text { Temperature of } \\
\text { oil in ( } \mathbf{~}^{\mathbf{C}} \mathbf{C}\end{array}$ & $\begin{array}{c}\text { Time for gas ON to observed } \\
\text { flame (min) }\end{array}$ & $\begin{array}{c}\text { Concentration of } \\
\text { CO at fire point } \\
\text { (PPM) }\end{array}$ \\
\hline 1 & Groundnut Oil & 337 & $8: 30$ & 958 \\
3 & Sunflower Oil & 345 & $9: 20$ & 665 \\
2 & Mustard Oil & 329 & $14: 30$ & 592 \\
4 & Soybean Oil & 330 & $10: 30$ & 448 \\
\hline
\end{tabular}

When concentration of $\mathrm{CO}$ is plotted against oil temperature (Fig. 12), it was found that there is a limit of oil temperature beyond which concentration of $\mathrm{CO}$ increases very sharply. This sudden increase of $\mathrm{CO}$ concentration is indication of fire event. From Table 4 it can be seen that at $300{ }^{\circ} \mathrm{C}$ the $\mathrm{CO}$ emissions is very high as compared to that at $200{ }^{\circ} \mathrm{C}$. The inhalation of this high concentration of $\mathrm{CO}$ can be very harmful. It may lead to death. Also it shows that the increase in oil temperature highly affects the rate of combustion and formation of $\mathrm{CO}$ due to incomplete combustion. The difference in $\mathrm{CO}$ concentration at AIT in Table 5 is also investigated.

Fig. 12 shows that for all four oils, the safer heating corresponding to $\mathrm{CO}$ concentration $<200 \mathrm{ppm}$ and oil temperature $\leq 250{ }^{0} \mathrm{C}$. These limits provide a scope to design a safety system for kitchens. As, measurement of temperature while cooking is not feasible. The thermocouple was not made part of the final safety system. Fig. 13 shows the variation of rate of change of $\mathrm{CO}$ concentration vs. time $(\mathrm{d}[\mathrm{CO}] / \mathrm{dt})$. It was seen that the rate of concentration change for all oil is more or less limited within $10(\mathrm{ppm} / \mathrm{s})$. Beyond that limit the oil catches fire. Table 6 shows that minimum response time between $\mathrm{d}[\mathrm{CO}] / \mathrm{dt}=10$ and fire point.

Table 5: CO emission (PPM) at different temperatures $\left(200{ }^{\circ} \mathbf{C}, 300{ }^{\circ} \mathbf{C}\right)$

\begin{tabular}{cccc}
\hline S. No. & Oil Types & CO (PPM) at 200 ${ }^{\mathbf{0}} \mathbf{C}$ & CO (PPM) at 300 $^{\mathbf{0}} \mathbf{C}$ \\
\hline 1 & Groundnut & 85 & 446 \\
2 & Sunflower & 87 & 242 \\
3 & Mustard & 89 & 199 \\
4 & Soybean & 31 & 94 \\
\hline
\end{tabular}

Table 6. Uncertainty analysis of 23 experiments conducted with the developed system

\begin{tabular}{|c|c|c|c|}
\hline S. No. (Oil type) & $\begin{array}{c}\text { Time(s) at } \\
\text { system alarm signal } \\
(\mathrm{d}[\mathrm{CO}] / \mathrm{dt}>\mathbf{1 0})\end{array}$ & $\begin{array}{c}\text { Time(s) at } \\
\text { occurrence of } \\
\text { visible flames }\end{array}$ & Response Time \\
\hline 1. (Groundnut) & 420 & 500 & 80 \\
\hline 2. (Groundnut) & 425 & 480 & 55 \\
\hline 3. (Groundnut) & 490 & 550 & 60 \\
\hline 4. (Groundnut) & 530 & 605 & 75 \\
\hline 5. (Groundnut) & 480 & 595 & 115 \\
\hline 6. (mustard) & 515 & 635 & 120 \\
\hline 7. (mustard) & 525 & 545 & 20 \\
\hline 8. (mustard) & 1155 & 1255 & 100 \\
\hline 9. (mustard) & 970 & 1005 & 35 \\
\hline 10. (mustard) & 1060 & 1095 & 35 \\
\hline 11. (Sunflower) & 1225 & 1255 & 30 \\
\hline 12. (Sunflower) & 425 & 470 & 45 \\
\hline 13. (Sunflower) & - & 520 & - \\
\hline 14. (Sunflower) & 860 & 880 & 20 \\
\hline 15. (Soybean) & 900 & 930 & 30 \\
\hline 16. (Soybean) & 620 & 635 & 15 \\
\hline 17. (Soybean) & 1020 & 1035 & 15 \\
\hline 18. (Soybean) & - & 510 & - \\
\hline 19. (Soybean) & 1010 & 1035 & 25 \\
\hline 20. (Soybean) & 515 & 535 & 20 \\
\hline
\end{tabular}



21. (Soybean)
22. (Soybean)
920
990
70
23. (Soybean)
460
475
15
445
455
10

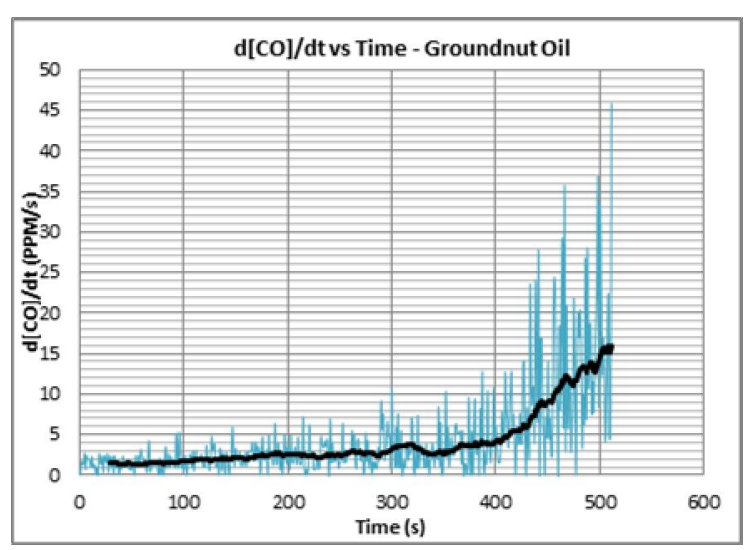

Fig.13(a)Groundnut oil-rate of change of $\mathrm{CO}(\mathrm{PPM})$

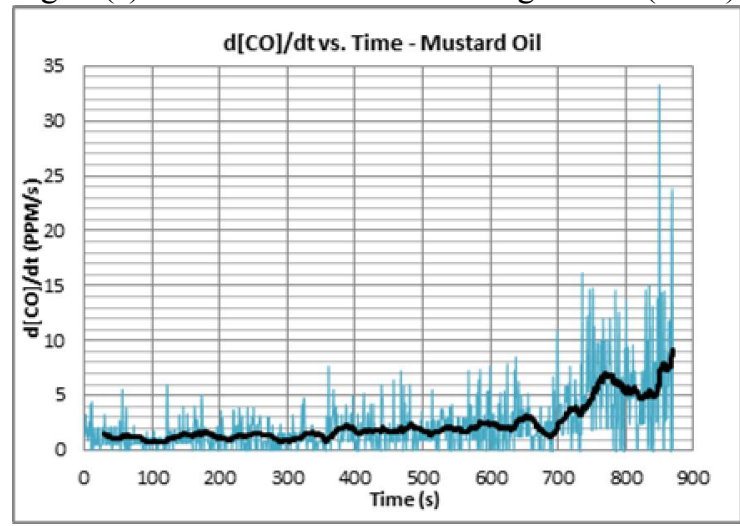

Fig.13(c)Mustard oil-rate of change of CO(PPM)

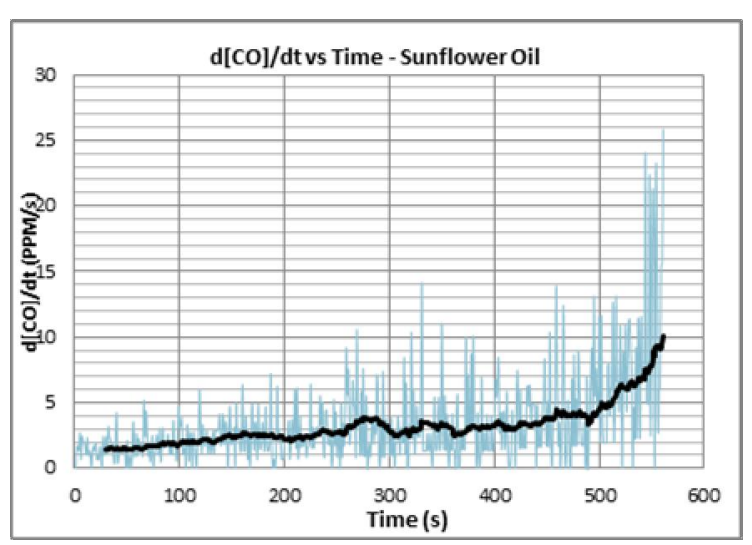

Fig.13(b)Sunflower oil-rate of change of CO(PPM)

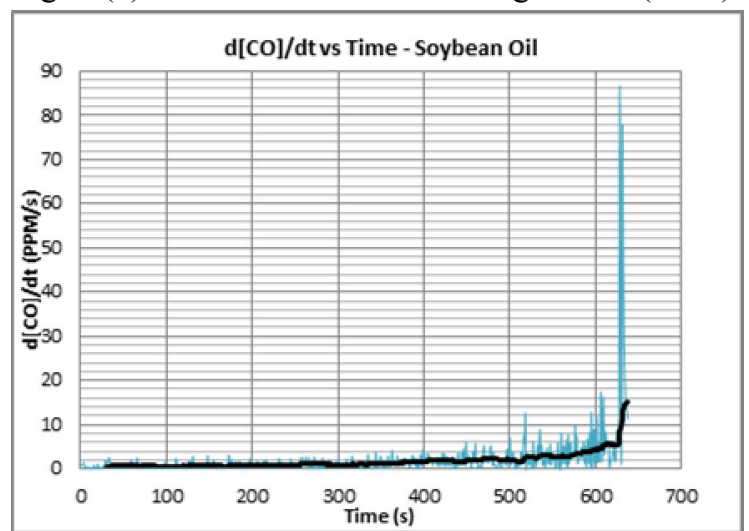

Fig.13(d)Soybean oil-rate of change of CO(PPM)

Fig. 13: Derivative of concentration of CO with respect to time vs. time plot

There were several experiments conducted before proposing the safety system. In the paper 4 experiments are described in detail and details of other experiments can be seen in Table 6. From these experiments we have found that the parameter $\mathrm{d}[\mathrm{CO}] / \mathrm{dt}$ could be used quite efficiently in prediction of the occurrence of fire. While performing above experiments we were continuously tracking the change in $\mathrm{d}[\mathrm{CO}] / \mathrm{dt}$ value by taking moving point average of 30 observations (with an interval of 5 second between consecutive observations). We concluded that whenever the magnitude of this averaged value goes above 10 (Fig. 13), there is a very high possibility that oil may catch fire. We are defining "time of catching of fire" by a conspicuous observation which is, visible flame. All these oils being hydrocarbons, burn with a visible flame. Thus in the designed prototype an alarm signal was set at moving point average of $\mathrm{d}[\mathrm{CO}] / \mathrm{dt}$ value $=$ 10.

Table 6 shows the System safely prevented overheated oils from "catching fire" in 21 out of 23 experiments giving us a success rate of $91.3 \%$. Also with our present system we have zero false positive alert occurrences. However, in two of the experiments, system failed to give an alarm signal well before time. The system fail motivated us to improve the algorithm and add a threshold to CO Concentration (PPM) concerning the health hazards related to the inhalation of $\mathrm{CO}$ gas.

Figure 14 explains the proposed algorithm for fire detection system; the kitchen environment was instrumented to take data from three sensors namely CO sensor, LPG sensor and Motion (PIR). The data taken from these three sensors were fed to an Arduino microcontroller. The controller was programmed 
according to algorithm presented in fig. 14 to give an alarm, shut-off LPG supply and send SMS to the user.

Figure 15 shows that there is not much variation in the amount of $\mathrm{CO}$ that evolves at $200{ }^{\circ} \mathrm{C}$. However, as temperature increases $\left(300{ }^{\circ} \mathbf{C}\right.$ or above), the amount of $\mathrm{CO}$ decreases with increase in the $\%$ saturation of oil. This is mainly because different oil has different $\%$ saturation. It was found that the $\%$ saturation of oil is directly related to the amount of $\mathrm{CO}$ evolved.

Similar to CO detection and oil temperature, the LPG sensor attached to the cooking table was also tested for its sensitivity; LPG was allowed to pass through the burner without any ignition. The LPG valve was open for few seconds ( $10 \mathrm{~s}$ to $50 \mathrm{~s})$ and then closed. Fig. 16 is the response from the LPG sensor. LPG concentration in air $>50 \mathrm{ppm}$ can be susceptible to fire event. Though, the LFL of LPG is about 21000 PPM but having a small among of LPG is also not acceptable in the kitchens. The attached motion sensor can detect the presence of moving body in front of the LPG stove. In case there is nobody for a certain time interval (In this study 5 min was set) it can give the alarm.

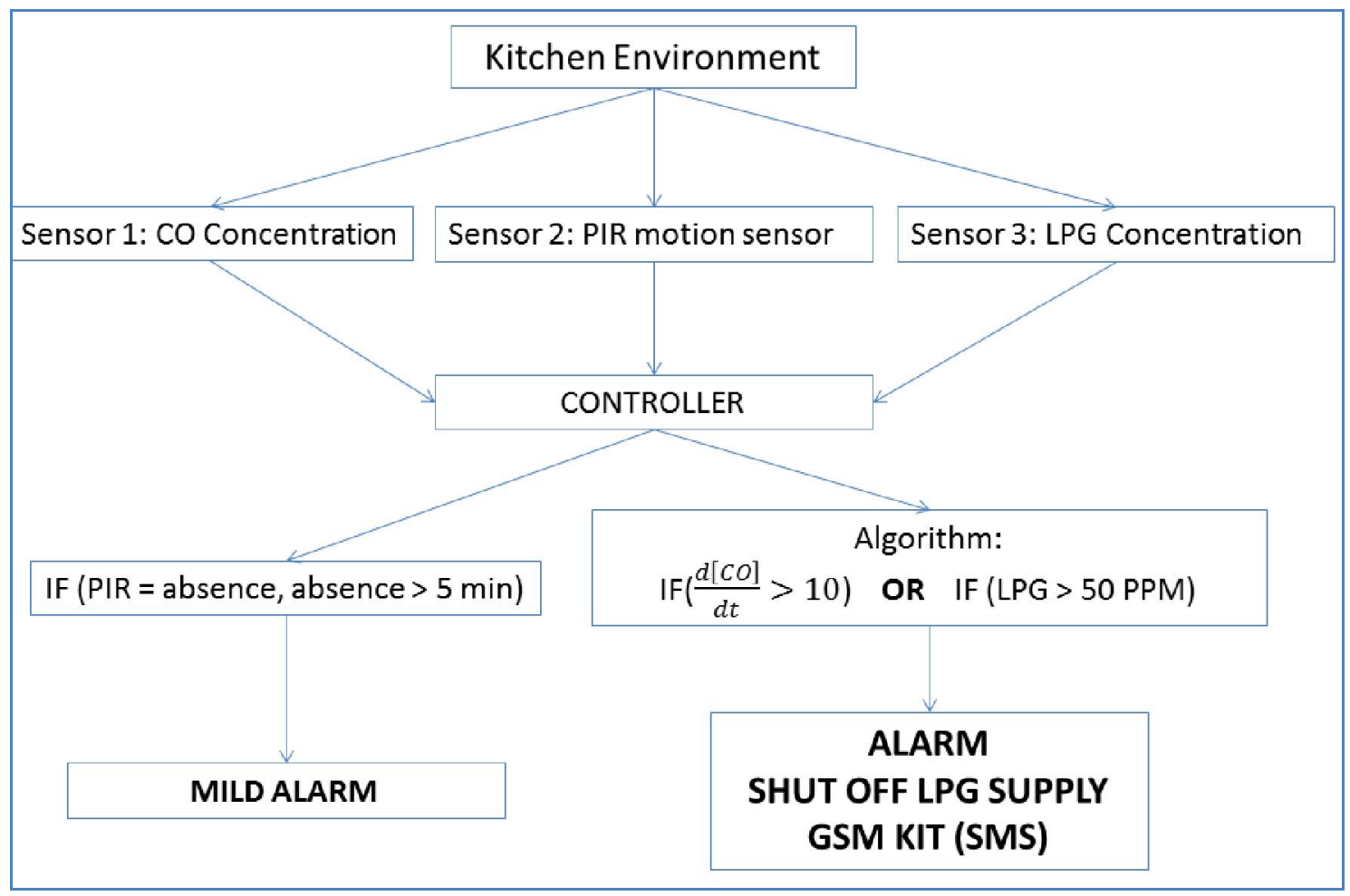

Fig. 14. Proposed algorithm for fire detection system 


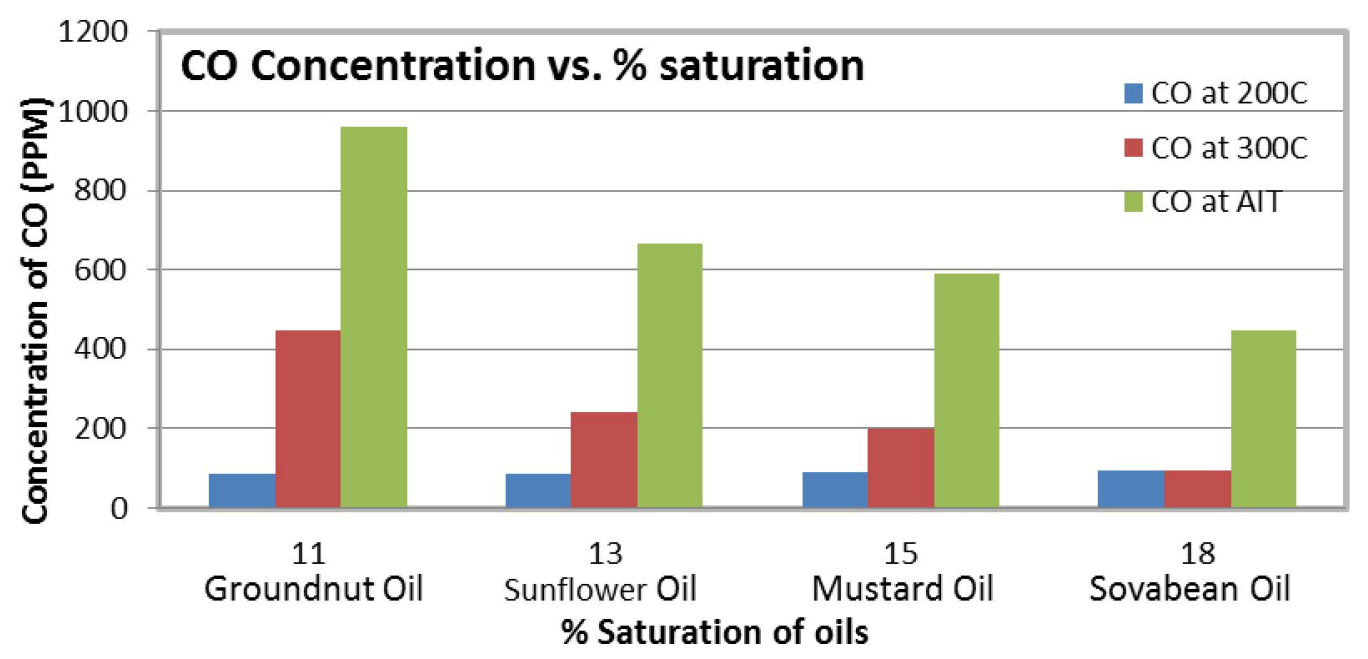

Fig. 15: \% saturation of oil vs. concentration of $\mathrm{CO}$ at auto ignition temperature

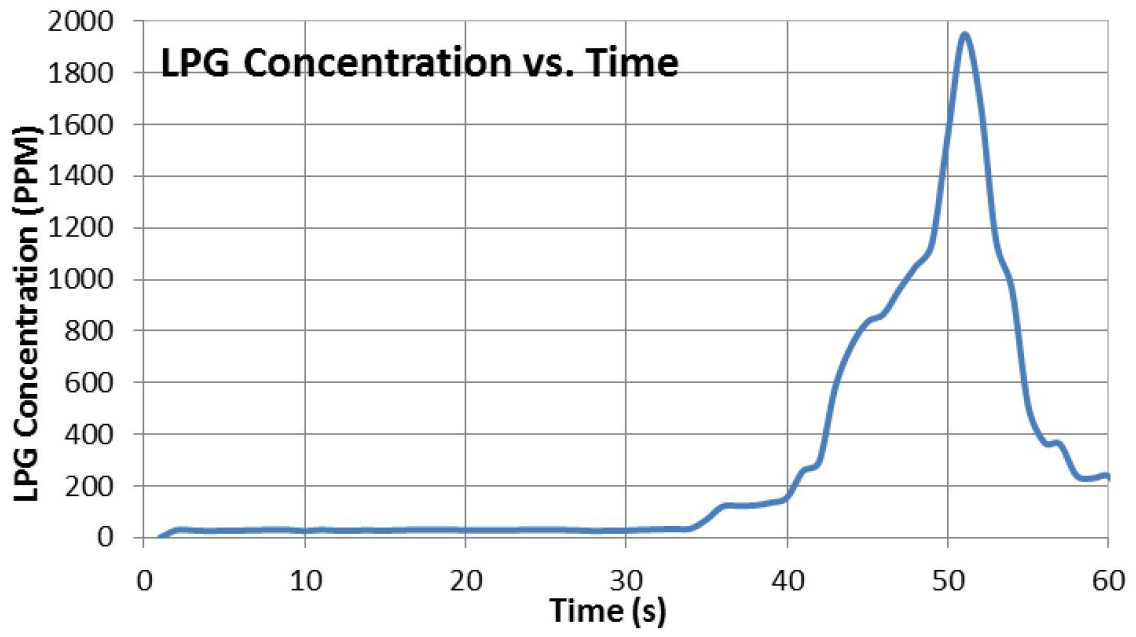

Fig. 16. LPG concentration with time during leakage of LPG

Thus using the limiting value of CO concentration, LPG concentration and the time for motion sensor, a prototype of the fire detector system is proposed and tested for several times. The kit could be a very good safety system for Indian kitchen where lot of cooking oil is used for preparing food in presence of LPG. Integration of LPG sensor and motion sensor is an additional safety feature for any LPG leakage and unattended cooking for which definite time can be set. In case of overshoot of the any of the set value, the detection kit provide alarm, SMS, phone call etc. At the same time it can cut the LPG supply to stop any anticipated fire event. The kit could be useful to save lives and property.

\section{CONCLUSIONS}

A study was conducted to design a multi-sensor safety system for Indian kitchens. Heating experiments were conducted on four different edible oils in a typical Indian kitchen experimental setup, using LPG as a fuel. It was found that parameter: $(\mathrm{d}[\mathrm{CO}] / \mathrm{dt})$ could be used very effectively to predict fire occurrences while heating oils. Experiments show that whenever the value of this parameter crosses value of 10, there is a very high possibility that the oil being heated can catch fire. Integrating these values within the microcontroller along with the LPG sensor and motion sensor a multi-sensor safety system is designed and prototyped which in any of the adverse conditions $(\mathrm{d}[\mathrm{CO}] / \mathrm{dt}>10$ ) can provide alarm, SMS and emergency phone call. Also it can automatically switch off the LPG supply and avoid any unwanted situations. More testing could be done to tune the performance of the algorithm for the range of stoves and ventilation design parameters in the Indian kitchen. 


\section{ACKNOWLEDGEMENT}

We are highly thankful to Underwriters Laboratories (UL) for providing the research grant to carry out this work at IIT Gandhinagar. Special thanks to Mr. August W. Schaefer for his continuous support to IIT Gandhinagar.

\section{REFERENCES}

[1] Tropical Fire Research Series “December and Holiday Fires" U.S. Department of Homeland Security, U.S. Fire Administration, National Fire Data Center, Emmitsburg, Maryland 21727 Volume 6, Issue 4, December, 2006

[2] U.S. Fire Administration/National Fire Data Center, Structure Cooking Fires, Topical Fire Research Series, Volume 5 - Issue 6, August 2005

[3] John R. Hall Jr., "Home Fires involving cooking equipment", Fire Analysis and Research Division, National Fire Protection Association, February, 2008

[4] “NFPA's Latest Estimates of Home Cooking Fires 2010”, National Fire Protection Association Fact Sheet-January2012-01, www.nfpa.org

[5] "Young professional most at risk from kitchen fires", News release in 2010, 6, September 2010, http://www.london-fire.gov.uk/news/NewsReleases2010_PR1438.asp\#.UkLV6D-NBso

[6] "Accidental deaths in India", National Crime Records Bureau, Ministry of Home Affairs, Government of India, 2011, www.ncrb.gov.in

[7] Fact sheet N³65, "BURNS”, Fact sheets, Media Center, World Health Organization, May, 2012, www.who.int

[8] “Census of India 2001 \& 2011”, Ministry of Home Affairs, Government of India, 2010-11, www.Censusindia.gov.in

[9] Antonette D'Sa and K.V. Narasimha Murthy, "Report on use of domestic cooking fuel option in India”, International Energy Initiative (IEI), Bangalore, June 2004, www.iei-asia.org

[10] Luis A. Cestari, Clarence Worrell, James A. Milke, Advanced fire detection algorithms using data from the home smoke detector project, Fire Safety Journal, Volume 40, Issue 1, February 2005, Pages 1-28

[11] Gottuk, D. T.; Peatross, M.J.; Roby, R. J. and Beyler C. L. (2002), Advanced fire detection using multi signature alarm algorithms, Fire Safety Journal, 37, 381-394

[12] Qiang, L., (2011), Estimation of fire detection time, Procedia Engineering, 11, 233-241

[13] Wang, S-J., Jeng, D-L and Tsai, M-T, (2009), Early fire detection method in video for vessels, J. Systems and Software, 82(4), 656-667

[14] B.V. Mehta, "India's Overall Demand and Supply of edible oil with special reference to rice bran oil", $1^{\text {st }}$ Thainland conference on Fats and Oils, Naresuan University, Phitsanulok, Thailand, $16^{\text {th }}-$ $17^{\text {th }}$ May' 2013 